\title{
FOTOGRAFIA, MEMÓRIA E ARTE. Sobras de Geraldo de Barros ${ }^{1}$ Sandra Maria Lúcia Pereira Gonçalves ${ }^{2}$
}

\begin{abstract}
Resumo: O presente artigo reflete acerca das relações que se estabelecem entre a fotografia e a memória, e no caso específico da série fotográfica Sobras, de Geraldo de Barros, que inspira este trabalho, a transformação dessa matéria (fotografia e memória) em objeto artístico. Três são os eixos temáticos trabalhados: fotografia, memória e arte. Para refletir acerca da relação entre memória e fotografia, a perspectiva teórica é bergsoniana. A relação entre percepção e memória será abordada e a partir desta relação emerge um conceito fundamental, o de imagemcristal que, acredita-se caracterizar a série Sobras. Em relação à arte, o texto é ancorado em autores que abordam as vanguardas históricas e suas relações com a fotografia, bem como aqueles que tratam da Fotografia Moderna no Brasil. Ao final, os três eixos são convocados de modo que se possa entender a relação da série Sobras com a memória e sua inserção no universo da arte e da imagem-cristal.
\end{abstract}

Palavras-Chave: Fotografia. Arte. Memória.

\begin{abstract}
This is an essay about the relations between photography and memory, and in a specific case, the photography series Sobras - in translation, Leftovers, by Geraldo de Barros, which inspires the present work with the transmutation of that matter (photography and memory) into an artwork. There are three thematic axes to be considered in this essay: photography, memory and art. To think about the relation between memory and photography, the perspective is the bergsonian ideas. The relationship between perception and memory will be approached, and form this relation emerges a central concept: that one of crystal-image that is believed to distinguish the series Sobras. When the subject is art, this essay is anchored in the thoughts of authors who approached historical vanguards and its relations with photography, as well as those who approached Modern Photography in Brazil. At the end of this essay, the three axes will appear in a way that it is possible to understand the relation of the series Sobras with the memory and its insert in the world of art and crystal-image.
\end{abstract}

Keys-Word: Photography. Art. Memory.

Há alguns anos li um conto do escritor cubano Virgílio Piñera (1989), chamado $O$ Álbum. A narrativa gira em torno de um evento fotográfico, ou seja, a leitura pública de imagens fotográficas de um álbum fotográfico familiar e de viagens. Tal evento acontece de tempos em tempos. As sessões de leitura são concorridíssimas e todos buscam sentar nas

\footnotetext{
${ }^{1}$ Versão de trabalho apresentado ao GT Estudos de Cinema, Fotografia e Audiovisual do XX Encontro da Compós. Porto Alegre, junho de 2011.

${ }^{2}$ Professora Doutora, Adjunto III, área fotografia, do Departamento de Comunicação da Faculdade de Biblioteconomia e Comunicação da Universidade federal do Rio Grande do Sul. Mestrado e Doutorado na Escola de Comunicação da Universidade federal do Rio de Janeiro. Fotodocumentarista. Email: sandrapgon@terra.com.br.
} 
primeiras fileiras, lugar que torna possível a visualização das imagens contadas. A leitura dessas imagens não tem hora nem dia para acabar, pode durar meses. Tudo depende da disposição da dona do álbum frente às imagens que lhe surgem no decorrer das páginas. $\mathrm{Na}$ apresentação do álbum, narrada em $O$ Álbum, a Dama (assim a personagem é chamada no conto), ao iniciar a exposição, resolve escolher a esmo a imagem a ser exibida. Trata-se de uma fotografia de seu casamento, momentos antes de partir o bolo.

$\mathrm{O}$ relato da personagem sobre a imagem-registro começa, bifurca-se e apega-se a pequenos detalhes que a levam para outras histórias que não mais dependem do referente e se encontram fora do quadro fotográfico. Torna-se claro ao longo da narrativa que, ao mesmo tempo em que certifica e autentica, a imagem se abre, no relato, para a imaginação e mesmo para a ficção - entre a captação e a interpretação da imagem há um abismo, diz Berger (1999). No conto referido, a fotografia de família, imagem-lembrança, serve de ponto de partida para outras histórias; reconstruindo ou recriando uma memória feita de lembranças que se fazem e refazem permanentemente na imagem. Ao imaginar as imagens contaminadas de lembranças, a dama atualiza um passado virtual, latente. Um passado que retorna na imagem; reconstrói e mesmo cria, ultrapassando as evidências do documento (imagem-registro). Ao modo bergsoniano (BERGSON, 2010) poder-se-ia dizer que a Dama, ao tornar-se espectadora de seu passado, fosse por ele guiada e atualizasse, na leitura, suas múltiplas possibilidades.

Soma-se à leitura do conto referido, o meu encontro com a obra artística Sobras de Geraldo de Barros ${ }^{3}$, que move o presente artigo. Na obra, o artista trabalha com antigos álbuns fotográficos de família e de viagens. De modo semelhante à Dama, através de técnicas variadas, Barros atualiza suas lembranças na forma de novas imagens, recriando a referência para criar novos sentidos (recorta, cola, monta, remonta). Ao utilizar esses recursos, Barros ressalta o caráter efêmero da permanência/referência fotográfica. Diferentemente da fotografia, imagem fixa e congelada que atesta a presença de um referente, as lembranças mudam constantemente, sujeitas que são; às emoções e ao tempo.

A partir desses encontros cresceu em mim o desejo de refletir sobre as relações que se estabelecem entre a imagem fotográfica e a memória e, no caso específico, de Sobras, sobre a transformação dessa matéria em objeto artístico. Para tanto se buscará pensar de que modo se dá a apreensão dessas imagens pelo artista no contexto escolhido, a série fotográfica Sobras, em que as obras tangenciam a um só tempo o universo da técnica e da arte, do aparelho e da

\footnotetext{
${ }^{3}$ Geraldo de Barros (1923 - 1998) - artista brasileiro, trabalhou com diferentes meios de expressão (gravura, pintura, desenho), entre eles a fotografia. Realizou apenas dois projetos fotográficos - as séries Fotoformas (1950) e Sobras (1998).
} 
memória. O corpo do artigo será dividido em três eixos temáticos, a saber: fotografia (como se constitui como imagem), memória (como interfere no processo de captação/visualização da imagem) e arte (o campo de produção de Sobras). De modo mais efetivo, esses eixos irão se encontrar na tentativa de se pensar Sobras.

A respeito da relação entre memória e fotografia, a perspectiva teórica escolhida é a bergsoniana. A memória que aqui interessa não é apenas a do referente, do "isso foi" barthesiano (BARTHES, 1984), passado que pode ser alcançado linearmente a partir de um presente da imagem. A memória aqui a ser pensada é a que faz de si própria processo que, através da lembrança, contamina o olhar do presente e é, pelo presente, contaminada. Para esse fim são convocados, entre outros, autores filiados a Bergson (2010), a saber, Gilles Deleuze (2007), André Rouillé (2009), leitor de Deleuze e Bergson, e Fatorelli (2003). Para desenvolver a abordagem proposta, a relação entre percepção e memória será abordada. Dessa relação emerge um conceito fundamental para o desenvolvimento do texto, que é o de imagem-cristal, conceito de origem deleuziana, trabalhado aqui por Rouillé (2009) e Fatorelli (2003) e que acredito caracterizar o trabalho Sobras de Geraldo de Barros. Em relação à arte o texto será ancorado em trabalhos e autores que abordam a questão das vanguardas históricas e suas relações com a fotografia: Bajac (2005) e Newhall (1967), além daqueles que tratam especificamente da Fotografia Moderna no Brasil: Costa (2004; 2005) e Fernandes Junior (2003; 2006). Deste modo inclui-se e introduz-se a fotografia de Geraldo de Barros, artistafotógrafo. A partir daí serão imbricados os conceitos bergsonianos, trabalhados pelos autores indicados, de modo a entender a relação do trabalho Sobras, de Geraldo de Barros, com a memória e sua inserção no universo da arte e da imagem-cristal.

\section{Fotografia}

Neste começo, a fotografia é apresentada a partir de sua essência, de sua ontológica, a partir daquilo que a faz diferente de todas as outras imagens: a marca indelével de um referente que adere (BARTHES, 1984). Tal pensamento, como se verá, se isolado, é redutor por considerar a realidade apenas como um dado registrável. Após, somar-se-á à reflexão o extracampo fotográfico (aquilo que está na imagem, mas cuja referência não é material, imprimível), que envolve desde as opções do fotógrafo quando da obtenção da imagem (opções políticas, estéticas) até os usos posteriores dados a essas imagens. Será possível assim potencializar a condição de imagem da fotografia (plural, variável), que não se esgota na designação, no mero registro de um referente. Rouillé (2009; 1998) e Dubois (1998) servirão 
de base a esta construção. A reflexão possibilitará a compreensão do papel do fotógrafo, de suas escolhas e recusas quando da obtenção da imagem: "o olhar está restrito e guiado pelos interesses presentes do fotógrafo, e pela amplitude de sua vida passada" (ROUILLÉ, 2009: 225). Levando-se em conta que o objeto que provoca a nossa reflexão, Sobras, surge de um debruçar-se do fotógrafo sobre suas próprias imagens (Barros atualiza suas lembranças) será oportuno demonstrar a parte desse observador singular, também operador dessas imagens. Tal procedimento ajudará no entendimento das relações, ambíguas, entre criação e interpretação e o papel da memória nesses dois momentos.

Pode-se afirmar, tendo-se por base a história da técnica fotográfica, que a imagem fotográfica foi marcada por sua semelhança e contiguidade com o real por ela representado, conferindo-lhe o estatuto de cópia fiel do mundo. A fotografia, nesse modo de pensar, tornase a autenticação de existência daquilo que é representado - por suas características, especialmente a fidelidade com que reproduz o real, leva o seu receptor a confundir o referente com a sua representação. Tal característica de analogon (BARTHES, 2000) da imagem fotográfica se deve a sua natureza técnica, a seu processo automático, baseado na física e na química e à pretensa neutralidade da máquina fotográfica. Cabe então à fotografia o discurso da referência. Vista como mediação neutra, impessoal e não cultural, a linguagem fotográfica se assenta na ideia Barthesiana de "mensagem sem código". A visão da fotografia como espelho do real tem perpassado a história da técnica fotográfica, naturalizando seu uso ideológico e político.

A descrição acima corresponde ao que Dubois (1998), em sua obra O Ato Fotográfico, pensando as relações da fotografia com o real, chama de "a fotografia como espelho do real" (DUBOIS, 1998: 26), a primeira de três diferentes posições epistemológicas sugeridas pelo autor, que marcaram a história da fotografia no século XIX e XX. A fotografia é vista como o discurso da mimese. No mesmo texto, Dubois, utilizando a teoria dos signos de Pierce ${ }^{4}$ para pensar a questão da referência na fotografia, assemelhará a primeira posição ao ícone, ou seja, aquele signo que tem com o seu referente uma relação de semelhança. Apesar de ainda encontrarem-se vestígios dessa posição na contemporaneidade, seu reinado corresponde ao século XIX e meados do século XX, principalmente na fotografia documental e jornalística. Entre as décadas de 1940 e 1960 um discurso desconstrutor, oriundo de diferentes áreas do saber, agiria sobre a leitura das imagens fotográficas. Teorias como a da imagem, inspiradas

\footnotetext{
${ }^{4}$ Dubois (1998) indica o ano de 1895 como referência a publicações de Pierce sobre semiótica.
} 
na psicologia da percepção de Arnheim ${ }^{5}$ (1992), estudos sociológicos apontando o quanto há de construção ideológica nos discursos (BOURDIEU, 2003) e estudos na antropologia que colocavam em questão o uso da fotografia como dado etnográfico bem como passível de leituras similares, alertaram para o quanto de construído possuía a imagem fotográfica. A fotografia, então, seria vista como transformadora do real, provocando "efeitos de real". Esta segunda posição, segundo Dubois, corresponde, na teoria dos signos de Pierce, ao símbolo, aquele que possui com seu referente uma relação arbitrária, ou seja, a fotografia é, para essa corrente, um conjunto de códigos (social, cultural, estético entre outros) a serem decifrados. $\mathrm{Na}$ terceira posição apresentada por Dubois, tem-se certa volta ao referente, sem, contudo a “obsessão do ilusionismo mimético" (DUBOIS, 1998: 53): a imagem fotográfica é vista como indissociável de sua "experiência referencial, do ato que a funda" (IDEM). Agora, a fotografia é traço de um real, na qual o objeto captado, insistentemente, retorna. Esta última posição, defendida por Dubois, ressalta sobremaneira o caráter indicial da fotografia, deixando a questão da semelhança, do ícone em um segundo plano. Para Dubois, há uma hierarquia entre essas três posições: primeiro a fotografia é índice, traço de um real, depois ela é um ícone, semelhança e por fim, símbolo, adquire sentido.

Segundo Rouillé (2009), nos anos 1980, o discurso do índice, ao se somar à retomada das teorias de Pierce se potencializou e serve "de verdadeira vulgata para os discursos acerca da fotografia" (ROUILLÉ, 2009: 190). Apesar do valor de distinguir o mérito semiótico da fotografia em relação às outras imagens e mostrar que a relação entre o mundo das coisas e a prova fotográfica, pode ser tanto de contiguidade quanto de semelhança, tais discursos têm a desvantagem de "relacionar as imagens a uma preexistência de coisas, das quais essas imagens, passivamente, só registrariam o vestígio" (Idem), reduzindo a fotografia "ao funcionamento elementar de seu dispositivo" (Idem). Há, segundo Rouillé (2009), nessa visão ontológica da fotografia uma recusa das singularidades e dos contextos, uma atenção exclusiva à essência. Para o autor francês, com quem se concorda, a questão ontológica da fotografia, sua essência (registro, vestígio) impediu durante longo tempo que se observassem seus referentes incorporais (CAUQUELIN, 2008), que vão além dos detalhes técnicos da tomada de imagem (mas também influenciados por eles) e que incluem a vivência do fotógrafo, suas percepções, sentimentos e desejos: "Um fragmento de vida, reminiscências de lugares, pessoas, tempo passado e presente, palavras trocadas, uma atmosfera de cheiros, cores, sabores, sons: um tecido frágil que tende a se desfazer se chegarmos perto demais e

\footnotetext{
${ }^{5}$ Para o autor, a desconstrução do realismo fotográfico baseia-se na observação da técnica e de seus efeitos perceptivos.
} 
cuja consistência é a fluidez" (CAUQUELIN, 2008: 2). Em outras palavras, não se nega o valor documental da imagem fotográfica, mas busca-se sua relativização, sua autonomia frente ao referente.

Contemporaneamente, com a crise da imagem documental, cujos valores se adequavam sobremaneira aos da sociedade industrial e moderna, e a consequente relativização do índice e do ícone, abre-se caminho para outras práticas que, ao negar o discurso da certeza referencial, aderem ao discurso do múltiplo, do híbrido potencializando a outra parte da imagem fotográfica, aquela que não se esgota na referência. Entre essas práticas, destaca-se: a fotografia-expressão praticada pelos fotógrafos, aquela em que a questão da escrita fotográfica, do autor e do Outro é potencializada; e a arte-fotografia, praticada pelos artistas, na qual a imagem fotográfica descolada do papel de documento do mundo adquire a função de matéria para a arte (ROUILLÉ, 1998); neste lugar situo o trabalho de Geraldo de Barros que, dentre outros meios, utilizou a fotografia como forma de expressão.

A seguir analisarei mais detidamente as relações que se estabelecem entre a fotografia e a memória, matéria prima trabalhada em Sobras, e deste modo tentando também compreender o papel do operador e do espectador quando da leitura (e recriação) da imagem. Na sequência voltarei à questão da arte como fotografia.

\section{Fotografia e memória}

Após o exposto, percebe-se que hoje o pensamento ao se debruçar sobre a fotografia o faz muito mais com o foco em seu processo de constituição como imagem (que envolve, além da referência, do objeto presente, os incorporais, referências "invisíveis" na imagem) ${ }^{6}$ do que sobre o ato da impressão. O pensamento sobre a expressão se mostra mais fértil, mas não esquece a designação, a descrição, a captação, o registro visto serem condição da imagem fotográfica. Para Rouillé "as fotografias ultrapassam cada vez mais a constatação para chegar à problemática, ultrapassam seus referentes materiais para exprimir questões mais gerais. A expressão tende a prevalecer ao atestado, à afirmação de existência” (ROUILLÉ, 2009: 196). Essa expressão é obra de um fotógrafo e será fruída por um espectador que ao se debruçar sobre a imagem o fará a partir de sua memória, mesclando os olhares permanentemente.

\footnotetext{
${ }^{6}$ Os incorporais seriam o não visível materialmente na imagem, desde os pontos de vista, os ângulos de tomada, as visadas, a composição até a "vida" do fotógrafo. Vida que envolve aspectos individuais e coletivos e que conformam a memória do operador (ROUILLÉ 2010: 202).
} 
O ponto de partida para pensar as relações entre fotografia e memória tem como foco os movimentos que levam à captação da imagem pelo fotógrafo. É a percepção do fotógrafo guiada pela memória acumulada de toda uma vida que se fará presente na imagem (BERGSON, 2010). Marque-se que no processo fotográfico, o fotógrafo se depara, segundo Rouillé (2009) com três temporalidades heterogêneas: o presente da ação (o fotógrafo frente à duração, a vida que passa diante de seus olhos), o tempo da captação (matemático, abstrato, do disparo mecânico) e uma terceira temporalidade, na qual a imagem é a um só tempo, um passado-futuro; passado das coisas e dos corpos, futuro do evento da imagem (sua expressão). É uma imagem latente, que se desdobra em dois movimentos antagônicos, mas que ao mesmo tempo se permeiam. Se o fotógrafo for o processador de sua imagem se abrirá uma quarta temporalidade, a do espectador de suas próprias imagens. Tornado espectador, o operador, ao se deparar com suas cópias, será ele também capturado pelo passado recente da tomada que, por sua vez, se mesclara com o presente da mirada. Frente as suas próprias imagens, "não é direta e simplesmente remetido ao passado findo do estado de coisas representado, mas tal passado se mistura com as lembranças (o passado contemporâneo) das etapas, das peripécias, das circunstâncias que presidiram sua realização" (ROUILLÉ, 2009: 210) - nesse jogo entre memória e percepção, o passado contamina o presente e é por ele contaminado. Embora possuam temporalidades diferentes, os processos perceptivos, em termos bergsonianos, parecem ser semelhantes para operador e espectador porque ambos estão, perceptivamente, embebidos pelo manto da memória através de suas lembranças. Explicita-se então como se dá esse processo, essa fina relação entre a fotografia e a memória: tudo se inicia com Bergson (2010) e sua descrição dos mecanismos da percepção e da memória.

De acordo com Bergson e seus leitores (citados no corpo deste texto), "a percepção é uma representação selecionada pelo corpo para a ação [...] a percepção pura parte das coisas [...] ela é impessoal. É preciso, portanto a contribuição de uma memória para que a percepção torne-se consciente e pessoal”, (VIEILLARD-BARON, 2007: 25). Ou seja, a percepção de algo se dá a partir de uma atenção, de um "saber" que a antecede, localizado na memória e resgatado como uma imagem-lembrança que vai dirigir a atenção e se mesclar ao objeto dado à percepção. A partir daí, formam-se como que circuitos entre o objeto percebido e a memória.

A cada nível de percepção e atenção, portanto de tensão, um novo circuito é gerado. Com o aprofundamento da percepção, sua concentração, novos circuitos são formados, partindo todos do objeto e a ele retornando. Esses circuitos se entrelaçam à volta do objeto, formados por memória, que embebe toda a percepção; vão alcançando camadas cada vez mais 
profundas da realidade e níveis mais elevados da memória. O mesmo objeto se insere repetidas vezes nos "vários circuitos de percepção e de memória, criando cada um uma imagem mental, uma "descrição", que tende a substituí-lo, a "apagá-lo", retendo dele apenas alguns traços, sempre provisórios" (ROUILLÉ, 2009: 212). O objeto permanentemente se renova, nunca é o mesmo. "Assim, criamos ou recriamos a todo instante. Nossa percepção distinta é verdadeiramente comparável a um circuito fechado, onde a imagem-percepção dirigida ao espírito e a imagem-lembrança lançada no espaço correriam uma atrás da outra" (BERGSON, 2010: 117) até um ponto de total indiscernibilidade.

Nesses circuitos de percepção e memória, existe um, o mais próximo à percepção imediata do objeto e que contém apenas o objeto "e a imagem consecutiva que volta para cobri-lo" (BERGSON, 2010: 119), onde o objeto se reflete como um duplo, criando de si uma imagem virtual ${ }^{7}$ que o envolve (e que rapidamente será envolvida pelos circuitos percepçãomemória), nesse lugar, dá-se, segundo Deleuze (2007), uma "coalescência" entre os dois, onde a indiscernibilidade seria total. "Há a formação de uma imagem bifacial, atual e virtual" (DELEUZE, 2007: 88), de uma imagem-cristal.

Nesse momento, fugaz, ainda não absorvido pelas lembranças, essa imagem é um cristal. Ou seja, como frisa Zourabichvili (2009), leitor de Deleuze, o cristal aparece no momento em que "o atual, vivido ou imaginado, é inseparável de um virtual que lhe é cooriginário, de tal maneira que se pode falar de "sua própria" imagem virtual. A imagem divide-se em si mesma, em lugar de se atualizar em uma outra, ou de ser a atualização de uma outra" (ZOURABICHVILI, 2009: 43). Deleuze (2007), em passagem do livro Imagem Tempo, sintetiza a constituição da imagem-cristal:

O que constitui a imagem-cristal é a operação mais fundamental do tempo: uma vez que o passado não se constitui depois do presente que ele foi, mas ao mesmo tempo, é preciso que o tempo se desdobre a cada instante em presente e passado, que por natureza diferem um do outro, ou, o que dá no mesmo, desdobre o presente em duas direções heterogêneas, uma se lançando em direção ao futuro e a outra caindo no passado. O tempo consiste nessa cisão, e é ela, é ele que se vê no cristal (DELEUZE, 2007: 102).

Um lugar de trajetórias imprevisíveis, de permuta entre atual e virtual, presente e passado, real e imaginário, um lugar de potência. Então, pode-se dizer, concordando com Rouillé, leitor de Bergson e Deleuze, que "perceber um objeto atual presente significa [...]

\footnotetext{
${ }^{7} \mathrm{O}$ virtual aqui é tomado na acepção de Pierre Lévy: “O virtual é como um complexo problemático, o nó de tendências ou forças que acompanha uma situação, um acontecimento, um objeto ou uma entidade qualquer, e que chama um processo de resolução: a atualização" (LÉVY, 1998: 16).
} 
associar-lhe uma imagem virtual que o reflita e envolva, e inseri-lo nos circuitos que o absorvem entre percepção e lembrança, real e imaginário, físico e mental” (ROUILLÉ, 2009: 213).

Fatorelli (2003), tendo como base o conceito deleuziano de imagem-cristal, explicitado acima, e tendo como critério a relação variável das imagens com o tempo e o espaço, utiliza o conceito para nomear as imagens fotográficas que não possuem como viés predominante a subserviência à referência (imagens presentes principalmente no universo da arte), possuidoras que são de realidades que não se confundem com ela. Segundo o autor, "autônomas, abstraídas do vínculo remissivo de origem, essas imagens situam-se num presente sempre renovado que desperta um passado e prenuncia um futuro igualmente abertos" (FATORELLI, 2003: 33); essas imagens são como presentificações, atualizações expressas em dados arranjos do visível. Provocam a suspensão do aqui e agora, possibilitando nexos com um imaterial, "uma potência de pensamentos [...] quando o que importa não é mais reconhecer, mas conhecer" (Idem). A potência dessa imagem está em ampliar o universo do visível, sua possibilidade de mobilizar múltiplas temporalidades. Para pensar a série Sobras de Geraldo de Barros, é com esse conceito de imagem-cristal que irei trabalhar.

\section{Arte e Fotografia}

Será abordada a seguir, a questão específica da arte e suas relações com a fotografia (vanguardas históricas e fotografia moderna no Brasil), introduzindo deste modo, o personagem deste artigo, Geraldo de Barros. Em seguida, serão imbricados os conceitos bergsonianos, trabalhados pelos autores indicados, Deleuze e Rouillé, entre outros, a fim de clarificar a relação do trabalho Sobras, de Geraldo de barros, com a memória e sua inserção no universo da arte e da imagem-cristal.

De modo a introduzir a questão da relação entre arte e fotografia, cabe uma pequena recuperação de uma das primeiras incursões do meio fotográfico na arte, no século XIX, a saber, o Pictorialismo. Marque-se que quando a fotografia surgiu, o status artístico lhe foi negado, visto o meio não possuir as características necessárias que até então marcavam uma obra de arte (BENJAMIN, 2002). Somou-se a isso o fato de, no período, a subjetividade estar expulsa da cena da representação; imagem-máquina excluiu a expressão humana, a mão do artista, segundo o entendimento da época. Buscar-se-á então, ressaltar as etapas sob o controle do autor no processo fotográfico. 
O movimento pictorialista teve seu apogeu entre os anos de 1890 e 1914 . Surgiu dentro dos fotoclubes, associações de amadores aficionados pela fotografia, sendo uma resposta à massificação que a prática fotográfica atingia com a industrialização dos equipamentos e materiais fotossensíveis (COSTA, 2004). Os temas abordados eram clássicos (retratos, nus, paisagens, marinhas), imitavam os estilos da época (romantismo, naturalismo, realismo, impressionismo). Utilizavam como técnica o processo de pigmentação controlada, que permite repetidas intervenções na cópia. O nível de dificuldade e a sofisticação técnica resultante fizeram outra vez, da fotografia, uma atividade para iniciados. Os pictorialistas lançaram mão de todos os meios à disposição para, literalmente, degradar a imagem fotográfica. Como frisa Costa "na tentativa de elevar-se à categoria de arte a fotografia abdicava de sua própria identidade" (2004: 26). Com as intervenções na cópia, a fotografia perdia sua referência a um objeto concreto, e seu caráter múltiplo abria o questionamento da fotografia como cópia da realidade, criando, segundo Costa, “condições propícias à superação do paradigma documental herdado do século XIX" (2005: 4).

No início do século XX, o movimento pictorialista teve suas estruturas abaladas. Os novos movimentos artísticos que surgiam então tomaram para si o meio fotográfico. A fotografia tornou-se um dos meios privilegiados na busca de uma nova visão, empenhada na crítica e na recusa de todas as formas artísticas do passado (inclusive as tentativas pictorialistas). Movimentos como o Dadá, o Suprematismo e o Construtivismo russo (que iria influenciar o concretismo brasileiro), o Futurismo, o Cubismo seguido pelo Surrealismo francês, permutaram com a fotografia. Inúmeros foram os artistas pertencentes a esses movimentos que utilizaram a fotografia. Entre eles, pode-se destacar Man Ray, artista americano, e Moholy Nagy, artista e teórico húngaro membro da Bauhaus, ambos inseridos no tecido cultural a que esses movimentos dão vida. Os dois utilizaram técnicas como a solarização e, por vezes, captavam a imagem fotográfica sem o uso da câmera (fotogramas), na tentativa de se afastar da fotografia convencional e seu determinismo visual; a fotomontagem, recurso também utilizado, permitia a destruição e a desmontagem da realidade. Na busca da expressão, os artistas optaram pelo acaso, em vez da composição dogmática. Esses artistas foram guiados por uma busca formal, na qual a significação dos objetos era praticamente eliminada. As técnicas mencionadas são visíveis no trabalho de Geraldo de Barros, como se terá oportunidade de observar. Man Ray e Moholy Nagy, assim como Geraldo de Barros, articularam a fotografia com outras manifestações visuais ${ }^{8}$.

\footnotetext{
${ }^{8}$ Importante marcar, dentre os movimentos de vanguarda, o surrealismo, grande consumidor e produtor de imagens fotográficas. Suas características técnicas perpassaram as vanguardas (solarização, fotogramas, fotomontagens,
} 
Em resumo, a fotografia, inserida dentro dos movimentos de vanguarda, traduziu-se, como coloca Costa, "pela pesquisa de autonomia formal e, consequentemente, pela negação da importância decisiva do referente" (2004: 30). Observa-se, nas vanguardas históricas, um primeiro movimento de descolamento, de relativização do referente que iria se potencializar na fotografia contemporânea. A partir daí começou a se formar um amálgama entre fotografia e arte, que se consolidou no último quarto do século XX com a arte-fotografia (ROUILLÉ, 2009; ROUILLÉ, 2008) que no Brasil, se pode dizer, teve em Geraldo de Barros um precursor.

\section{Fotografia moderna no Brasil}

No Brasil, no mesmo período, o espaço onde se praticava a fotografia com pretensão artística era os dos fotoclubes. Como nos congêneres europeus do final do século XIX e início do século XX, seguiam-se aqui os padrões da arte pictórica. Do mesmo modo como aconteceu na Europa, os ecos do modernismo no Brasil penetraram nos fotoclubes e, por meio de artistas pioneiros como José Yalenti, Thomas Farkas, German Lorca e Geraldo de Barros, produziu-se uma verdadeira revolução nesses espaços, bem como na fotografia brasileira. Destaca-se neste aspecto o Foto Cine Clube Bandeirante fundado em 1939, em São Paulo, que se caracterizou como uma escola, a Escola Paulista de Fotografia. Ressalta-se que segundo Costa a busca por uma estética modernista na fotografia brasileira, foi uma experiência coletiva, que reuniu pesquisas individuais que contribuíram para a instauração de "um novo olhar', numa ruptura clara com a prática acadêmica" (COSTA, 2004: 35). Tinham como desafio "romper com o isolamento a que a fotografia havia sido condenada até então no âmbito da produção e da reflexão artística, colocá-la em sintonia com uma realidade sóciocultural em profunda transformação e acertar o passo com o panorama internacional" (COSTA, 2005: 2).

A fotografia moderna no Brasil teve início em meados dos anos 1940, período no qual foram consolidadas ações que colocaram o país em um período de franco desenvolvimento (investimento de capital estrangeiro, expansão do mercado interno, consolidação de uma classe média, crescimento urbano, bem como iniciativas para alavancar o desenvolvimento industrial) (FERNANDES JUNIOR, 2003). No campo artístico, movimentos como o

colagens fotográficas, o "tremido", superposições de negativos e exposições múltiplas, enfim todos os tipos de manipulação em laboratório que fazem do meio uma experiência a serviço da exploração do imaginário ou do inconsciente) (BAJAC, 2005). 
Concretismo e o Neoconcretismo, com tendências abstracionistas, estavam em voga e marcaram a fotografia construtivista produzida por Geraldo de Barros e seus colegas. Entretanto, diferentemente de seus colegas, que na busca de uma nova linguagem respeitavam o processo fotográfico (fotografar, revelar, ampliar), Barros realizava intervenções nesse processo, rompendo com o processo fotográfico tradicional. Riscava os negativos com ponta seca, pintava-os com nanquim, guache entre outras coisas, "dando corpo a um profundo questionamento dos limites da linguagem fotográfica" (COSTA, 2004: 43). A concepção plástica de suas imagens fotográficas está ligada a sua produção como artista plástico construtivo, ou seja, a fotografia era matéria para o artista.

As técnicas utilizadas por Barros na busca de sua expressão artística iam desde o fotograma (utilizado por Man Ray e Moholy Nagy), às sobreposições de imagens, às intervenções nos negativos, passando principalmente pelo acaso. Apesar de dominar perfeitamente o procedimento, ele acreditava residir no erro e no acaso a criação fotográfica e considerava que o conhecimento técnico deveria ser o necessário para a sua expressão (BARROS, 2006). A partir dessas experimentações, Barros produziu a série fotográfica Fotoformas, exposta no Museu de Arte Moderna de São Paulo (MASP) em 1950. As imagens propostas na série apresentam-se como híbridos; não mais fotografia no sentido próprio do termo, mas matéria a serviço da arte. Na imagem abaixo (FIG. 1) se pode observar uma das imagens da série. Percebe-se neste trabalho uma busca pela abstração, um desligamento da referência como aquilo que define a imagem (cópia a partir de negativo recortado, posto entre duas placas de vidro).

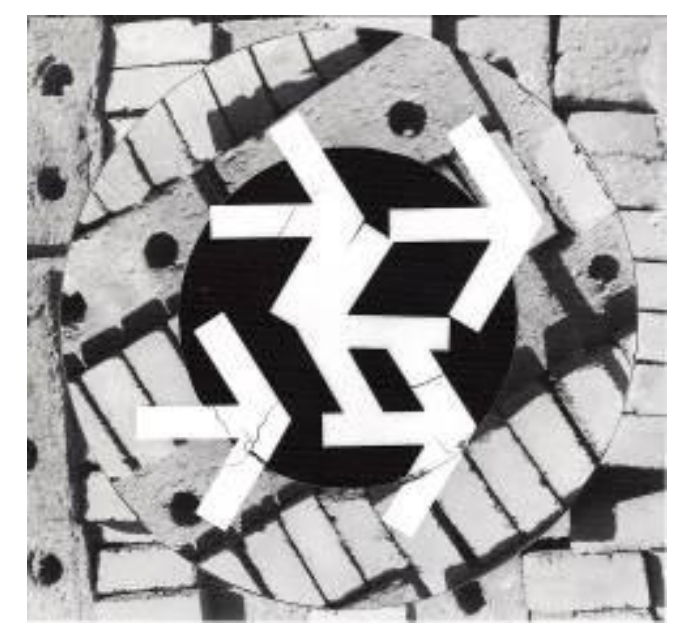

FIGURA 1 - Fotoformas, São Paulo, 1949.

FONTE - BARROS, 2006: 92. 
Em 1952, como membro do Grupo Ruptura ${ }^{9}$, ele expôs outra vez no MASP. Essa exposição foi considerada um dos marcos no processo de consolidação do concretismo no Brasil. Após esse período, Barros deixou de lado seus experimentos com a fotografia. Volta a eles em 1988, após uma série de quatro isquemias que o deixaram bastante debilitado - ficou com dificuldades na fala e na realização de movimentos. A volta de Barros à fotografia se deu através de antigas imagens de férias e viagens com amigos e a família. Auxiliado por sua assistente, Ana Moraes, transformou esse material em matéria para sua arte (FERNANDES JÚNIOR, 2006). Nasce então, a série Sobras, finalizada com sua morte em 1998, obra da maturidade na qual, através do filtro da memória, atualiza suas lembranças em obra artística. Neste lugar pode-se também vislumbrar a potência ainda viva de Fotoformas, série que alimenta a construção de Sobras. Inspirada nos autores trabalhados no corpo do texto segue uma breve leitura de Sobras.

\section{Sobras}

Ao trabalhar com seus antigos álbuns de família, Barros parte de imagens íntimas cuja dependência à referência é fundante. Álbuns, comumente, guardam memórias visuais de pessoas e momentos vividos e nesse tipo de imagem, a verossimilhança é desejada e esperada. Marque-se que não é como artista que ele fotografa a família e os amigos, mas como um amador produtor e destinatário de suas fotos. Entretanto penso que, como artista, ao se deparar com as imagens contidas nas caixas e álbuns ele tenha se sentido como Epimeteu ao abrir a caixa de Pandora, tentando reter de cada imagem futuros possíveis num passado que se mistura ao presente da mirada, futuros não previstos na referência que as imagens o remetiam. Frente a essas imagens, como observador (e operador) das cenas retratadas, o passado transborda no presente de seu olhar, um passado que se atualiza nas manipulações que realiza nessas imagens. Ou seja, acontece com Barros, na manipulação dessas imagens no presente da visada, um transbordamento do tempo, provocando uma fissura, um hiato no qual brota a imagem-cristal. É como um espelhamento, aquele do circuito mais curto relatado por Bergson (2010). Nesse lugar, os antagonismos cessam, não por acomodação, mas porque um é

\footnotetext{
${ }^{9}$ O Grupo Ruptura se opunha a toda a arte que havia sido feita no Brasil até então. O movimento concreto queria ampliar a esfera de atuação das artes, pensando e melhorando o ambiente urbano, modernizando o meio cultural brasileiro e, principalmente, socializando as artes e a cultura. Conferir em:http://www.sescsp.org.br/sesc/revistas/revistas_link.cfm?edicao_id=316\&Artigo_ID=4915\&IDCategoria=5626\&re ftype $=2$, acesso em 15 de dezembro de 2010.
} 
presença no outro, tudo é fluxo, atual e virtual, passado e futuro, sonho e realidade. Nesse lugar, Barros criou uma nova história para suas velhas imagens até então esquecidas.

Artista inquieto, preso a uma cadeira de rodas, Barros, em termos deleuziano, era puro $\operatorname{devir}^{10}$ na manipulação de seu material artístico. Por diferentes meios, sempre experimentais, fez intervenções nas antigas imagens mostrando-se esteticamente coerente ao seu passado construtivista (artista-fotógrafo, Barros não se rende, a verve construtivista não o abandona nos espaços da memória). Superpôs situações, lugares, formas, pessoas. Fez colagens simultâneas de negativo e positivo (nas imagens já ampliadas faz recortes, acrescenta fundos escuros, cria planos, corta, cola, colore), criando relações inauditas entre esses elementos. Nunca a repetição do mesmo; mas sim, a lógica processual que atualiza o dado e produz o novo. Em Sobras, a alegria da criação de um universo poético surgiu de modo incontornável.

Ao criar novas paisagens, situações e lugares, Barros subverteu o universo da fotografia e tornou único o múltiplo, criou a sua própria referência, ou melhor, se deixou invadir pelo passado virtual de suas lembranças que se atualizaram num entre-lugar (passadofuturo) de reconstrução permanente ao qual se dá o nome de presente, lugar da aventura do sentido. Observe-se a seguir duas dessas imagens (FIG. 2 e FIG. 3). Na figura 2, de formato quase panorâmico, podem-se observar esquiadores em um campo de neve. A configuração da imagem surpreende; campo a um só tempo, íngreme e plano (o trabalho compulsivo com a forma, os planos). Um misto de estranhamento e curiosidade move o olhar sobre a imagem, olhar não mais inocente, contaminado pelo próprio passado de quem a observa. Superposição de planos, personagens, emaranhados, linhas. Movimento, fluxo, dança. Multidão ou um? Como se um mesmo personagem ocupasse em simultâneo diferentes lugares. Ele ou eu? Por um breve momento eu estava lá. Eram minhas também essas lembranças de neve. Um último (?) estranhamento: no canto superior esquerdo, novo corte geométrico, forma imagem em negativo; céu negro, vazio, silêncio. Imagem intensa, suplementar e cristalina me permite como observador, compactuar ou mesmo inventar os seus segredos.

\footnotetext{
${ }^{10}$ Para Deleuze devir é "nunca imitar, nem fazer como, nem se conformar a um modelo, seja de justiça ou de verdade. Não há um termo do qual se parta, nem ao qual se chegue ou ao qual se deva chegar. Tampouco dois termos intercambiantes [...] Os devires não são fenômenos de imitação, nem de assimilação, mas de dupla captura, de evolução não paralela, de núpcias entre dois reinos." (DELEUZE apud ZOURABICHVILI, 2009: 48).
} 


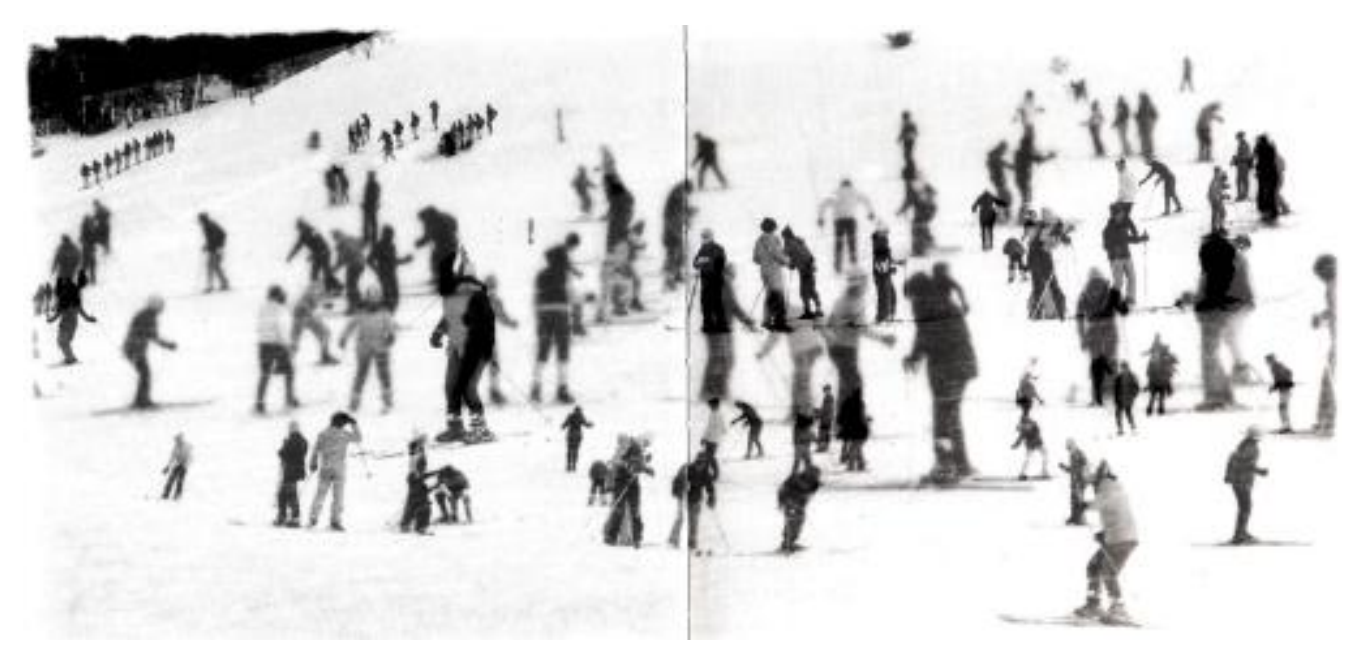

FIGURA 2 - Sobras, Argentina, s/d.

FONTE - BARROS in FERNANDES JÚNIOR, 2006: 62-3.

Na figura 3, novo estranhamento. Em uma bucólica e idílica imagem de um chalé entre campos de neve e floresta, um fragmento negro, um breu como um rio invade a imagem. Um novo signo fotográfico, desconcertante, é criado. Outra vez a colagem, a montagem radicalizada, fragmentos que escapam à ação determinista do referente. De novo sou tomada; através desse breu (hiato, falha), saio e entro na imagem num movimento a um só tempo compulsivo e criativo, proporcionado pela imagem-cristal; ao vislumbrá-la sou como Barros, capaz de inventar e perceber mundos ocultos, de transformar o material mimético, a transparência da imagem em viagem intensa do olhar.

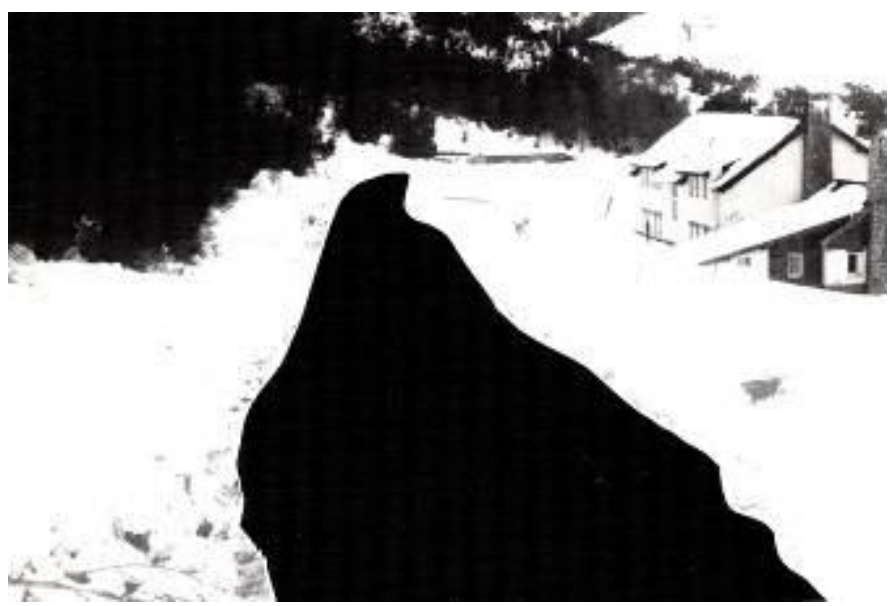

FIGURA 3 - Sobras, Argentina,s/d.

FONTE - BARROS in FERNANDES JÚNIOR, 2006: 79.

Parece-me conclusiva a importância de um olhar sobre o trabalho de um artista desde sempre contemporâneo, surgido no modernismo, porém integrado aos processos de criação contemporâneos. Para Barros, artista, a fotografia sempre funcionou como matéria para a sua arte. Na série Sobras, ele soube tecer a fina urdidura entre fotografia, memória e arte, criando 
as condições para o aparecimento da imagem-cristal. Imagem que alimenta não só o universo da arte, mas é também fecunda para ampliar o universo da fotografia aplicada (fotojornalismo e fotopublicidade) na comunicação. Sobras permite a quem observa participar do fluxo ininterrupto de sua criação. Barros apresenta o fluxo e convida à viagem. Para finalizar, considero sermos tributários ao trabalho pioneiro de Geraldo de Barros, visionário, ao introduzir o pensamento conceitual na fotografia brasileira. A partir de suas séries, Fotoformas e Sobras, a imagem fotográfica deixou de ser apenas uma cópia da realidade, provocando e sendo reflexão e pensamento. 


\section{Referências Bibliográficas}

ARNHEIM, Rudolf. Arte e Percepção Visual. São Paulo: Pioneira, 1992.

BAJAC, Quentin. La Photographie. L’époque Moderne 1880-1960. França: Gallimard, 2005.

BENJAMIM, Walter. A obra de arte na época de sua reprodutibilidade técnica. In: LIMA, L. (Org.). Teoria da Cultura de Massa. São Paulo: Paz e Terra, 2000. 221-254p.

BERGER, John. Modos de ver. Rio de Janeiro: Rocco, 1999.

BERGSON, Henri. Matéria e Memória. São Paulo: Martins Fontes, 2010.

BARROS, Geraldo. Fotoformas. São Paulo: Cosac Naif, 2006.

BARTHES, R.. A Câmera Clara. Rio de Janeiro: Nova Fronteira, 1984.

A mensagem Fotográfica. In: LIMA, L. (Org.). Teoria da Cultura de Massa. São Paulo: Paz e Terra, 2000. 325-338p.

BOURDIEU, Pierre. Un arte médio. Barcelona: Editorial Gustavo Gili, 2003.

CAUQUELIN, Anne. Freqüentar os incorporais: contribuição a uma teoria da arte contemporânea. São Paulo: Martins Fontes, 2008.

COSTA, Helouise. Escola Paulista de Fotografia - Uma vanguarda Possível? www.iar.unicamp.br/dap/vanguarda/artigos.../helouise_costa.pdf, 2005. Acesso em 13 de janeiro de 2011.

UFRJ. 2004.

; SILVA, Renato Rodrigues. A Fotografia Moderna no Brasil. Rio de Janeiro: Editora

DELEUZE, Gilles. A Imagem-tempo. São Paulo: Brasiliense, 2007.

DUBOIS, P. O Ato Fotográfico. Campinas: Papirus, 1998.

FATORELLI, Antônio. Fotografia e Viagem. Entre a Natureza e o Artifício. Rio de Janeiro: Relume Dumará: FAPERJ, 2003.

FERNANDES JÚNIOR, Rubens (Texto e organização). Geraldo de Barros. Sobras + Fotoformas. São Paulo: Cosac Naif, 2006.

Cosac \& Naif, 2003.

Labirinto de Identidades. Panorama da Fotografia no Brasil (1946-98). São Paulo:

LEVY, Pierre. O que é o virtual. São Paulo: Editora 34, 1998.

NEWHALL, BEAUMONT. L'histoire de La photographe. Depuis 1839 et jusqu'à nos jours. Paris: Bélier-Prisma, 1967. 
ROUILLÉ, André. A Fotografia. Entre o documento e a arte contemporânea. São Paulo: SENAC, 2009.

. Da arte dos fotógrafos à fotografia dos artistas. In: TURAZZI, Maria Inez (Org.). Revista do patrimônio Histórico e Artístico Nacional, no 27, 1998. 302-311p. VIEILLARDBARON, Jean-Louis. Compreender Bergson. Petrópolis, RJ: Editora Vozes, 2007.

ZOURABICHVILI, François. Vocabulário de Deleuze. Rio de Janeiro: Relume-Dumara, 2009. 


\title{
CIDADE, PERIFERIA E CULTURAS POLICENTRICAS Nízia Maria Villaça ${ }^{11}$
}

\begin{abstract}
Resumo: O texto "Cidade, periferia e culturas policentricas" busca por em relevo as novas articulações que se estabelecem entre cultura, corpo e cidade no desenvolvimento dos processos de subjetivação individuais e coletivos. Uma nova semiose se impõe entre emoções e afetos que desalojam a cultura dominante herdeira do iluminismo mobilizando todo um imaginário urbano regido pelos jovens e pela periferia.
\end{abstract}

Palavras-chave: Cidade. Culturas Extremas. Periferia.

\begin{abstract}
This essay tries to underline the new relations between culture, body and urban space in the development of the collective and individual subjectives in our days. A new sensibility appears moved by affects that mobilize the illuminist heritage, throught the actions of the periphery and youth extreme audacity.
\end{abstract}

Key-words: City. Extremes Cultures. Periphery

Nossas considerações sobre a cultura midiática buscam uma metodológica polifônica, contrária ao pensamento holístico ou às estatísticas comprobatórias. $\mathrm{O}$ objetivo é positivar as diferenças e acentuar os traços de desordenação das produções contemporâneas, notadamente juvenis, embora esta categoria não possa ser sintetizada numa subcultura e encontra-se em franca reconfiguração. Não se pretende trabalhar com conceitos de identidade cultural, subcultural ou contracultural já que, como bem acentua Canevacci, ${ }^{12}$ tais conceituações não são termináveis. Interessam-me, sobretudo, os artistas diaspóricos, arquitetos dissonantes e outras tipologias caracterizadas pela diferença. Tomando o termo cultura e relacionando-o à

\footnotetext{
${ }^{11}$ Professora do Departamento de Letras e Expressões da Escola de Comunicação da Universidade Federal do Rio de Janeiro. Email: nmvillaca@uol.com.br.

${ }^{12}$ CANEVACCI, Massimo. Culturas eXtremas: mutações juvenis nos corpos das metrópoles; tradução Alba Olmi. Rio de Janeiro: DP\&A, 2005.
} 
contracultura e à subcultura, a proposta é retirar a totalização implicada no conceito de cultura, abdicando também do movimento revolucionário da contracultura e da submissão de várias subculturas a um grau de cultura superior. Tal modelo não funciona mais. A dicotomia cultura hegemônica e cultura subalterna dissolveu-se, notadamente, a partir dos anos 90.

Por outro lado, as culturas que chamamos de "extremas" são policentricas, movidas pelo afeto e não se interessam pelo contra que se incluía na transformação política do mundo. ${ }^{13}$ Se a cultura ligava-se à expressão do caráter nacional, a subcultura herdava os limites do conceito de cultura de que era parte. Referindo-me às comunidades periféricas a partir deste questionamento, pergunto se não existe uma perigosa homogeneização quando falamos de tais grupos, efervescentes de diferenças que absolutamente não coincidem com as versões midiáticas uniformizantes para o bem ou para o mal. Para afastar o perigo das diferenças as ciências sociais estruturaram-se em torno da defesa da identidade, selecionando o homogêneo em detrimento do heterogêneo, uniforme contra o fragmentário, o singular contra o plural, as conexões contra as disjunções.

No exercício da pesquisa de campo de comunidades "periféricas", uma das primeiras descobertas é o encontro de diferenças, segmentos, parcialidades e fragmentos. O sub é plural e não inferior, como se poderia pensar a partir de uma leitura gramsciana. Perde-se a versão realista, própria do século passado, cuja função era caracterizar tipos, confirmar classes e posições sociais. Também não é o cenário romântico, reduplicando os humores das personagens e afirmando a identidade exuberante do solo nacional ou mesmo o espaço do modernismo, mais preocupado com a visão política da afirmação do nacional. Não mais uma ideologia homogeneizante, generalizadora, produtora de totalidade já dada, mas o espaço como alteridade provocadora de novas inserções.

A fisicidade geográfica perde sua estabilidade e passa a ser visivelmente elemento coestruturante da subjetividade contemporânea nas diversas fases da crise por que passa: da desertificação do "eu", engolido pelos simulacros da cena americana, aos investimentos mais inesperados, como assinala Pierre Sansot no livro Les gens $d u$ peu. ${ }^{14}$ Perde-se o padrão - ouro de avaliação do espaço. Entra-se em uma espécie de transespaço camaleônico.

Para Octavio Ianni, ${ }^{15}$ a dispersão mundial dos processos produtivos é acompanhada pelo desenvolvimento de recursos informáticos de integração, também em escala mundial. A informática e as telecomunicações desempenham um papel importante no processo das

\footnotetext{
${ }^{13}$ SODRÉ, Muniz. As estratégias sensíveis: afeto, mídia e política. Petrópolis, RJ.: Vozes, 2006.

${ }^{14}$ SANSOT, Pierre. Les gens du peu. Paris: PUF, 1991.

${ }^{15}$ IANNI, Octavio. A era do globalismo. 2 ed. Rio de Janeiro: Civilização Brasileira, 1996. p. 70.
} 
transformações urbanas, acelerando ritmos, generalizando articulações, abrindo novas possibilidades de dinamização das forças produtivas, criando meios rápidos, instantâneos e abrangentes de produção e reprodução material e cultural. O mundo adquire características de uma imensa fábrica, acoplada com um vasto shopping center e colorido por uma enorme Disneylândia. Tudo isso polarizado na rede de cidades globais desenhando o mapa do mundo.

A tensão entre o cosmopolitismo e o localismo progressivamente se acentua, culminando na descaracterização da própria cidade como centro aglutinador das experiências, produção e reflexão da condição moderna. Ao modelo fordista adiciona-se, no cenário pósmoderno desse final de século, a especialização setorializada do capitalismo flexível em que os centros de produção são dispersos e a correlação entre operário e indústria se fragmenta na medida em que as referências espaciais e os agrupamentos de classe são desestabilizados. A modernidade parece sacudir as paisagens do imaginário desenhando estranhas cartografias descentradas ou, paradoxalmente, as metrópoles acabarão por tornarem-se favelas como afirma Mike Davis, ${ }^{16}$ num espaço contínuo.

Interpretar a multiplicidade das experiências urbanas das metrópoles significa avaliar os sinais da modernidade contemporânea sem recair no determinismo tecnológico de uma distopia esvaziada de significação. Entretanto, em confronto com a indiferenciação e a desertificação promove-se, tanto na arquitetura que abandona o ideário funcionalista quanto nos movimentos de bairro, grupos e associações públicas e privadas a importância da sustentabilidade com apelo à cultura como processo gerando solidariedade e sendo vetor de uma economia criativa e ativa.

\section{A cidade nos contextos globais}

Pensar a cidade hoje em tempos de globalização e a aceleração das trocas impõe o recurso à discussão do paradigma comunicacional e sua capacidade de construção de sentido; impõe o apelo aos estudos culturais para pensar a ordem e a desordem, a identidade e a diferença já que a cultura se constrói exatamente no trânsito entre esses pólos; impõe pensar as estratégias do consumo que imprimem ao imaginário contemporâneo uma mobilidade que não se deixa aprisionar pelas organizações classistas e que vivem de apropriações e negociações inesperadas. A leitura do mundo se processa sempre mais por meio de uma semiologia em que a pegada publicitária, o gosto pelo espetacular, pelo assombro, tanto pode criar uma congestão informacional, como linhas de fuga ao paradigma dominante. A cultura torna-se central neste processo urbano inscrito no mundo globalizado e o corpo e suas

\footnotetext{
${ }^{16}$ DAVIS, Mike. Planeta favela; tradução Beatriz Medina. São Paulo: Boitempo, 2006.
} 
próteses participam e promovem sua dinâmica. As cidades se articulam ao panorama internacional sem deixar ter suas preocupações primordiais ligadas à proximidade e à capacidade criativa em seus territórios. O local e o global se recriam em contextos virtuais e também de proximidade: praças, ruas, bairros e cidades concretas relacionando o local e o global, a memória e a inovação.

A cidade contemporânea, portanto, se expande hoje nas periferias que constituem um formidável e heterogêneo movimento de formas, paisagens, modo de organização e modo de vida. A periferia oferece um potencial de experimentação tanto para os atores que as constroem, como pelos habitantes que as vivem e os pesquisadores que as analisam. Participa do complexo da reorganização da cidade e é importante orientar a pesquisa no sentido não das categorias fechadas (centro e periferia), mas das situações de transição, evocando novas potencialidades. As periferias parecem obrigar os pesquisadores a pensar fora das categorias estabelecidas. Por outro lado e paradoxalmente, essa construção desses espaços se inscreve também numa dinâmica de uniformização, proveniente de modelos internacionais. É sobre este jogo entre normalização e inovação que nos perguntamos. Qual a responsabilidade dos atores políticos, das mídias, dos arquitetos urbanistas, dos geógrafos, nesta produção de sentido? Assim, nossa questão refere-se ao jogo dialético inovação/normalização no seio das periferias urbanas, tendo a moda como vetor. Seriam as periferias territórios à deriva? Territórios a serem contornados, barrados, murados? Ou nelas encontramos provocações para novos modos de funcionamento urbano que nos obrigam a pensar fora das categorias estabelecidas fugindo das classificações imobilizantes?

A globalização traz em seu bojo uma abertura dos processos de identidade, uma grande variedade de "posições de sujeito". Nas sociedades da modernidade tardia, a concepção de identidade é mais perturbadora e provisória, caracterizada por rupturas, descontinuidades e deslocamentos, em oposição às sociedades tradicionais que perpetuavam o passado. Áreas diferentes do globo são postas em interconexão, desalojando o sistema social de suas relações espaço-temporais tradicionais, provocando novas articulações e uma concepção problemática de identidade. Quanto mais a vida social se torna mediada pelo mercado global de estilos, lugares e imagens, pelas viagens internacionais, pelas imagens da mídia e pelos sistemas de comunicação, mais as identidades parecem flutuar livremente numa espécie de supermercado cultural. As novas tecnologias informáticas não são apenas instrumentos de percepção ou utensílios de produção, mas dispositivos de conexão e/ou de desconexão de formas onde o sentido se produz. Uma reciclagem atinge praticamente todos 
os domínios da cultura contemporânea, notadamente da tecnociência, da moda e das artes, com grande exuberância de processos de agenciamento das singularidades diferenciais.

É no interior desta dinâmica que o imaginário da moda vai, progressivamente, contaminando de homogeneização global, os lugares mais afastados e, simultaneamente, dotando de variedade locais a linguagem globalizada. A ação das cidades aparece como uma pedra angular da Agenda 21 da Cultura ${ }^{17}$, em que está é entendida como desenvolvimento solidário, luta pela liberdade, justiça e inclusão. O desenvolvimento local requer a imbricação entre as políticas culturais e as outras políticas públicas, sociais, econômicas, ambientais e urbanísticas com a participação do cidadão. O item que fala de cultura, sustentabilidade e território é da máxima importância e se articula com a criatividade das periferias para a inclusão social. O reconhecimento da dimensão econômica da cultura deve possibilitar e contribuir para a identidade local, a atividade criativa e a continuidade do emprego. É importante que o documento Agenda 21 da Cultura tenha sido utilizado por muitas cidades para desenvolver a dimensão cultural de suas políticas urbanas, tal como Bogotá, Montreal e outras. Nosso foco vai em direção do incentivo à cultura nas dimensões citadas impedindo sua instrumentalização para fins publicitários no momento em que, sem dúvida, a periferia é uma das pautas do momento.

\section{A corporeidade na cidade: da distinção ao estilo}

$\mathrm{O}$ uso do termo corporeidade remete à complexidade do seu entendimento não só como biologia, cultura das aparências, mas também nas suas relações com o mundo como fator social total. O corpo não é objeto de conhecimento do qual se possa dispor, não é algo que se coloca diante de nós, mas faz oscilar a cesura que se tenta colocar entre o pesquisador e ele mesmo. A questão da corporeidade representa uma interrogação contemporânea à sociedade da imagem, fotográfica e cinematográfica no momento em que ela diz respeito tanto às sociedades que se constroem, quanto aos conhecimentos que estudam suas ficções. A pergunta chega junto com a crise da matriz cientista e a passagem do conhecimento à imprecisão, instabilidade e à emoção. No lugar da segurança, ameaça da abjeção. Ora, o urbano a que somos convocados hoje não é mais a cidade como território, como gestão de espaços, como distribuição de atividades, mas de uma relação à cidade onde a corporeidade desempenha uma intrigante evidência e impregna a cidade, perturbando as categorias

\footnotetext{
${ }^{17}$ A Agenda 21 da Cultura foi aprovada em 2004 por cidades e governos locais de todo o mundo comprometidos com os direitos humanos, a diversidade cultural, a sustentabilidade, a democracia participativa e a criação de condições para a paz. In: Revista Observatório Itaú Cultural / OIC, n. 5 (abr/jun. 2008). São Paulo: Itaú Cultural, 2008. p. 14.
} 
clássicas (dentro/fora, privado/público, real/imaginário, aqui/lá). O urbano faz surgir não uma confusão, mas ambiguidade, temporalidade onde a fugacidade perene, o traçado invisível tornam-se elementos ativos na maneira de fazer e de sentir. Não é mais somente o indivíduo que se localiza na cidade. É uma relação consigo mesmo que se complica com a intervenção da aventura urbana. Novas relações com o mundo surgem e dão lugar ao indecidível, ao indeterminado e ao indefinido, apesar do desejo contemporâneo de uma comunicação generalizada e transparente.

Focalizamos a moda como fator de mobilidade social e individual, atitude cultural que entre outras artes vem acentuar o caráter dinâmico da cena contemporânea, trabalhando com o imaginário de misturas. Agora ela passeia pela periferia. Lugares como Caxias, município da baixada fluminense tornam-se on. Seu centro de confecções festejou o sucesso com desfile de Carlos Tufvesson em passarela estendida na Praça do Pacificador, foco do Fashion Caxias. Travestis desfilam na Mem de Sá criações próprias e param o trânsito da Lapa. Unhas postiças enormes, argolões dourados e lenço Louis Vuitton na cabeça, Luana Muniz declara enfática: "queremos mostrar que somos úteis e visíveis na sociedade". A visibilidade urbana estimula a moda que, segundo Georg Simmel, ${ }^{18}$ se não quer mudar o mundo, pretende arrumá-lo com um novo olhar. Ela ressemantiza o espaço e, na sua dimensão simbólica, organiza a vida social por meio das aparências partilhadas pelos diversos grupos. A publicidade e o consumo são alguns vetores desta construção de superfícies em que o sentido desliza jogando com o up and down dos indivíduos e lugares. Ser cutting edge é importante para se distinguir da massa e, sobretudo, os jovens de tribos diversas parecem estar sempre prontos para um clic.

Tradicionalmente a moda tinha uma função de distinção, como acentuou Bourdieu, ${ }^{19} \mathrm{e}$ os espaços e fronteiras acompanhavam a ordenação das classes, profissões, gêneros, faixasetárias. Balzac soube ler essas diferenças. Na história, alguns movimentos que marcaram a moda encarnavam revoltas pelo estilo e a desconstrução do mood anterior. Patrice Bollon, ${ }^{20}$ em A moral da máscara, narra a verdadeira luta simbólica das diversas manifestações marcadas pelos artifícios da aparência: Merveilleux, Zazous, Dândis ou Punks, são alguns dos exemplos.

\footnotetext{
${ }^{18}$ SIMMEL, Georg. La parure et autres essais; traduction et presentation Michel Collomb, Philippe Marty et Florence Vinas. Paris: Éditions de la Maison des sciences de 1'homme, 1998.

${ }^{19}$ BOURDIEU, P. Distinction: a social critique of the judment of taste. Cambridge: Harvard University Press, 1984.

${ }^{20}$ BOLLON, Patrice. A moral da máscara. Rio de Janeiro: Rocco, 1997.
} 
Se os anos 50 pertenceram a Copacabana, primeira praia a lançar moda, nas décadas seguintes novos points da Zona Sul e do Brasil fizeram eco nos jornais, revistas e blogs, determinando atitudes e comportamentos. A importância das ruas na moda tem um momento chave nos anos 60, quando se desenvolve o sport-wear e a moda unissex. Londres dita moda. As butiques se disseminam. Carnaby Street ou Kings Road tornam-se verdadeiros cenários entre música contínua, luzes, num entra-e-sai em que o movimento da rua é incorporado ao comércio. Progressivamente, a cidade oferece novas possibilidades tornando-se sempre mais inesperada, transversal. Nem mão, nem contramão. Tudo parece ser permitido e a velocidade da mudança dos trajetos caminha em ziguezague. Sequencialmente acelerou-se a desconstrução das oposições e multiplicaram-se os looks, a partir de novos dados culturais. A moda de rua inspira sites, blogs, fotologs e as tendências são simultâneas e em rede.

O movimento fashion, sempre mais fluido, parece obedecer a duas estratégias principais, uma delas conta as novidades como segredos e encontra verdadeiros cofres para os fashionistas. Ruas de bairros nem tão nobres escondem jovens estilistas que se associam para mostrar seus produtos. Em contrapartida, temos movimentos de ocupação geral como o Fashion Rio, São Paulo Fashion Week, feiras diversas e um pontilhado kitsch de camelôs. A construção do tempo/espaço urbano vai interferindo no imaginário das pessoas que se sentem aventureiras em suas descobertas das senhas de acesso fashion ou incluídas nas grandes festas. A cidade vira locação e cenário. Simultaneamente, o shopping vira cidade e a rua vira mall.

Diante do esfacelamento dos paradigmas que orientaram o projeto moderno de viés normativo na sociedade do consumo e do espetáculo, a moda se produz como arquivo e vitrine do ser/parecer, fabricando selfs performáticos por meio de sutis recriações dos conceitos de verdade, de bem e de belo. Materializa-se uma est-ética.

\section{O Rio midiático}

A cidade responde aos nossos medos e desejos. É carne e pedra, pertence a nossa corporalidade e acolhe tantas versões quantos forem os olhares sobre ela; "de uma cidade não aproveitamos as suas sete ou setenta e sete maravilhas, mas a resposta que dá a nossas perguntas". ${ }^{21}$ A cidade torna-se um caleidoscópio de padrões e valores culturais, línguas e dialetos, religiões e seitas, modos de vestir e alimentar, etnias e raças, problemas e dilemas, ideologias e utopias.

${ }^{21}$ CALVINO, Ítalo. Cidades invisíveis. São Paulo: Companhia das Letras, 1990. p. 44. 
O Rio de Janeiro é exemplarmente o resultado das narrativas que se criaram e se criam nas ciências sociais, na literatura, na música e, sobretudo, na mídia, em constante interação com a vivência de seus habitantes. O Rio colonial e sua transculturação mal ajambrada, sua lascívia e seus excessos fora do padrão da metrópole; o imaginário do luxo cosmopolita da capital federal se promovendo nos salões; a construção e promoção dos encantos naturais da cidade maravilhosa; e, mais recentemente, a explosão dos discursos sobre o Rio violento, sobre a cidade esquartejada, atravessada pela miséria. Impossível fixar hoje qualquer dessas imagens como preponderante. O Rio feito de points turísticos, o Rio que lança moda, é também o dos arrastões.

Diante do esfacelamento da realidade é comum ver a mídia produzir uma espécie de curadoria da cidade, conjugando a narrativa do Rio Maravilha, Rio do turismo e da moda e o Rio violento e marginal. Neste contexto é interessante apontar o aumento da variedade narrativa sobrre a cidade que vai encontrar na periferia protagonistas para uma infindável repaginação. Nesta dinâmica surge tanto a voz das comunidades, quanto a da indústria cultural.

Carlos Diegues, promotor de "5 X Favela", filme que vem agora dirigido por cinco habitantes da periferia fala da nova linguagem audiovisual do "cinema de retomada" sobre a periferia: "agora temos um ponto de vista diferente. Um ponto de vista de dentro está levando "5 X Favela" - agora por nós mesmos" $" 22$ Este novo olhar sobre as favelas é uma constante onde a reurbanização substitui a erradicação e a exposição de abril deste ano no Museu da Casa Brasileira, “Cidades Informais do Século 21", dá pistas sobre esta mudança. A mudança começou no Rio que em 1968 urbanizou três favelas: Brás de Pina, Mata Machado e Morro União, gerando em 1994, Favela-Bairro. Remoção agora só quando se trata de área de risco. O programa pioneiro da Favela-Bairro marca o fim da influência do modernismo na urbanização, que previa um modelo único de cidade e encarava a favela como um desvio a ser corrigido, como sublinhou Sérgio Magalhães que atuou no programa brasileiro nessa área www.mcb.org. ${ }^{23}$

Hoje, a mídia dá destaque espetacular às mudanças das favelas e à valorização dos imóveis em seu entorno. Tal fato parece desviar-se do espírito da Agenda 21 para deixar que o fator econômico se transforme no vetor principal das negociações. Compram-se casas, alugam-se lajes para festas, contratam-se castings para desfiles, descobrem-se talentos

\footnotetext{
${ }^{22}$ FONSECA, Rodrigo. "O morro vai a Cannes". In: $O$ Globo, 16 de abril de 2010, p. 1. Segundo Caderno.

${ }^{23}$ CARVALHO, Mario César. "Exposição revela um novo olhar sobre as favelas". In: Folha de S. Paulo, 8 de abril de 2010, p. E-4. Ilustrada.
} 
exportáveis. Torna-se missão delicada o diálogo sobre sustentabilidade, transculturação e cultura cidadã. A favela Dona Marta é a grande vedete, a favela show e, de alguma forma, está exigindo maior reflexão sobre a euforia narrada pela mídia onde matéria de página inteira praticamente não comenta o teor cultural das parcerias e negociações sublinhando o humor e deslumbramento dos atores sociais da comunidade que, segundo a matéria, nem se interessam por vezes pelas celebridades que freqüentam o morro. Se os movimentos comunitários buscam aumentar a auto-estima das comunidades, a do Dona Marta já está bem lá no alto, dispensando os encontros e ações propostas por pesquisadores como tive oportunidade de observar. Dizia a coordenadora do grupo de moda "Costurando Ideais" que não estava interessada em projetos com a UFRJ, pois, não se interessava em criar cooperativa para efeitos de poder dar recibos contra os benefícios recebidos. Segundo ela, a Prefeitura estava bem ali sem exigir nada em troca do incentivo turístico à região. A situação geral da narrativa midiática é confusa entre inauguração de bondes turísticos, elevadores (no Cantagalo), muros e ações de pacificação ora retratadas como plenamente vitoriosas, ora ameaçadas pela venda de drogas a céu aberto em espaços já ocupados pelas UPPs (Unidades de Polícia Pacificadora). No Morro da Providência onde proximamente as UPPs estarão em ação, três jovens foram mortos pelo simples fato de descer de um baile funk. Ação do Exército que não respeitou o espaço de ação da polícia estadual. ${ }^{24}$

A superficialidade dos relatos da mídia parece sugerir o sucesso definitivo das periferias assediadas por diretores de filmes, artistas e turistas. O êxito está presente na manchete "Favelas viram as grandes estrelas", ${ }^{25}$ mostrando que as favelas andam mesmo em alta na indústria cultural made in Rio. Por ocasião do carnaval na Marquês de Sapucaí as Escolas de Samba Portela, Unidos de Vila Isabel e Estação Primeira de Mangueira trouxeram carros alegóricos com representações bem particulares dos morros cariocas. Na Azul e Branco de Madureira, a favela simboliza com o carro "Conquistando a liberdade", a inclusão digital como forma de contribuir para a paz no Rio. Também as UPPs são apontadas no enredo como solução para a cidade. As diversas ligações entre comunidades e a cultura da moda, da música, sem dúvida mereceriam análises mais apuradas por parte das matérias jornalísticas que preferem ressaltar as cores vivas projetadas pelas novas obras sem detalhes para o modus operandi das parcerias que geram sustentabilidade. A opinião da comunidade vem narrada num registro que oscila entre passividade e deslumbramento. A desinformação sobre o

\footnotetext{
${ }^{24}$ TARDÁGUILA, Cristina. "O Exército, o político, o morro e a morte”. In: Revista Piauí, Ano 4, N. 46, julho 2010. p. 34-39.

${ }^{25}$ GALDO, Rafael. "Favelas viram as grandes estrelas". In: $O$ Globo, 14 de fevereiro de 2010, p. 18. Rio.
} 
assunto periferia inclui a pintura da fachada das favelas entre as quais está incluída a do Morro do Alemão que atualmente é sede da maioria dos traficantes provenientes das zonas ocupadas pelas UPPs. ${ }^{26}$

\section{Imagens periféricas}

O cinema hoje abdica em parte do fardo sociológico que carregava no cinema novo preocupando-se mais em captar o estilo pessoal dos atores sociais. Um bom exemplo é o filme "Sonhos roubados", de Sandra Werneck, em que três amigas vivem o dia-a-dia da favela construindo seus destinos no cruzamento das relações familiares, amorosas e de trabalho. Tudo fazem pelo consumo e pelo "estilo" numa série de escolhas que nos faz pensar em Gilles Lipovetsky ${ }^{27}$ e seu $O$ império do efêmero quando fala dos processos de personificação construídos incessantemente. As meninas e seus corpos oscilam numa constelação de valores e escolhas que parecem se equilibrar e equivaler num clima de deriva que ao final do filme parece resultar em liberdade prazerosa. Transar ou não transar, pintar o cabelo ou não, escolher este ou aquele objeto, procurar o pai, fazer festa de quinze anos, ajudar o avô, namorar presidiário etc, etc. Um exemplo perfeito da deriva a que se refere Sennett $^{28}$ ao descrever o capitalismo flexível.

Nossa hipótese é que a mídia no afã de criar novos olhares sobre a periferia continua alternando a demonização deste mundo com a crescente implementação de ficções românticas que se inclinam em variadas direções. No cinema, valores como liberdade de opções, estratégias de resistência e comportamentos estilosos na modelagem sex and the city são exemplos. Discutimos a real possibilidade de intervenção e recriação dos sentidos pelos atores sociais da periferia as possíveis manipulações da indústria cultural. Grande parte dos relatos da mídia contemporânea não apresenta um grau de processualidade que permita refletir sobre as interações entre a comunidade e as instituições estatais e/ou privadas que se dedicam a criação da sustentabilidade destas áreas que na cidade começam a serem ocupadas/pacificadas pelas UPPs cercadas por muros a espera da Copa do Mundo ou das Olimpíadas. Quando chegamos à Cidade do Rio de Janeiro passando pela Linha Vermelha podemos apreciar os simulacros da favela que estes painéis substituem: casario pobre, grafites e outras representações criadas frequentemente no computador.

\footnotetext{
${ }^{26}$ BASTOS, Isabela; MAGALHÃES, Luiz Ernesto. "Cores vivas nas favelas". In: $O$ Globo, 24 de fevereiro de 2010, p. 16. Rio.

${ }^{27}$ LIPOVETSKY, Gilles. O império do efêmero: a moda e seu destino nas sociedades modernas; tradução Maria Lúcia Machado. São Paulo: Companhia das Letras, 1989.

${ }^{28}$ SENNETT; Richard. A corrosão do caráter: as consequências pessoais do trabalho no novo capitalismo; tradução Marcos Santarrita, 13 ed. Rio de Janeiro: Record, 2008.
} 
Nosso propósito é tentar refletir como a periferia afirma, negocia ou recusa a imagem disseminada pela mídia, o que está sendo realizado em contatos não sistemáticos com algumas comunidades. O depoimento de Ferréz é significante:

E a mudança? Orientar sobre gravidez precoce, sobre o uso de drogas, montar uma campanha real para nosso meninos e meninas desvalorizados, estigmatizados, pelos olhos da elite, do próprio povo e por todos os meios de comunicação. Não podemos só mostrar a consequência, temos que mostrar a causa (FERRÉZ, 2006: A3).

\section{Referências bibliográficas:}

BASTOS, Isabela; MAGALHÃES, Luiz Ernesto. "Cores vivas nas favelas". In: O Globo, 24 de fevereiro de 2010. Rio.

BOLLON, Patrice. A moral da máscara. Rio de Janeiro: Rocco, 1997.

BOURDIEU, P. Distinction: a social critique of the judment of taste. Cambridge: Harvard University Press, 1984.

CALVINO, Ítalo. Cidades invisíveis. São Paulo: Companhia das Letras, 1990.

CANEVACCI, Massimo. Culturas eXtremas: mutações juvenis nos corpos das metrópoles; tradução Alba Olmi. Rio de Janeiro: DP\&A, 2005.

CARVALHO, Mario César. "Exposição revela um novo olhar sobre as favelas". In: Folha de S. Paulo, 8 de abril de 2010. Ilustrada.

DAVIS, Mike. Planeta favela; tradução Beatriz Medina. São Paulo: Boitempo, 2006.

FERRÉZ. “Antropo(hip-hop) logia”. In: Folha de S. Paulo, 5 de abril de 2006. Opinião.

FONSECA, Rodrigo. "O morro vai a Cannes". O Globo, 16 de abril de 2010. Segundo Caderno.

GALDO, Rafael. "Favelas viram as grandes estrelas". In: $O$ Globo, 14 de fevereiro de 2010. Rio.

IANNI, Octavio. A era do globalismo, 2 ed. Rio de Janeiro: Civilização Brasileira, 1996.

LIPOVETSKY, Gilles. O império do efêmero: a moda e seu destino nas sociedades modernas; tradução Maria Lúcia Machado. São Paulo: Companhia das Letras, 1989.

Revista Observatório Itaú Cultural / OIC, n. 5, (abr/jun, 2008). São Paulo: Itaú Cultural, 2008. 
SANSOT, Pierre. Les gens du peu. Paris: PUF, 1991.

SENNETT, Richard. A corrosão do caráter: as consequências pessoais do trabalho no novo capitalismo; tradução Marcos Santarrita, 13 ed. Rio de Janeiro: Record, 2008.

SIMMEL, Georg. La parure et autres essais; traduction et presentation Michel Collomb, Philippe Marty et Florence Vinas. Paris: Éditions de la Maison des sciences de l'homme, 1998.

SODRÉ, Muniz. As estratégias sensíveis: afeto, mídia e política. Petrópolis, RJ.: Vozes, 2006.

TARDÁGUILA, Cristina. "O Exército, o político, o morro e a morte”. In: Revista Piauí, Ano 4, N. 46, julho 2010. 